\title{
Glycated albumin is a better indicator for glucose levels than glicated hemoglobin in patients with diabetes mellitus on insulin therapy
}

\author{
Alvina*, Pusparini*, Meiyanti**, and Lie T.Merijanti***
}

\section{ABSTRACT}

\section{BACKGROUND}

Diabetes mellitus (DM) is a metabolic disease with a large incidence in the world and constitutes a global health problem. By 2030 it is estimated that there will be around 439 million people suffering from DM. Diabetes mellitus is a metabolic disease caused by a lack or absence of the hormone insulin. In type $2 \mathrm{DM}$ pharmacotherapy can be given one of which is insulin. To monitor therapy, random blood glucose, glycated hemoglobin (HbA1c) and glycated albumin (GA) levels can be examined. The objective of this study was to determine the relationship of glycated albumin and glycated hemoglobin $(\mathrm{HbA1c})$ with random blood glucose in insulin-treated diabetics.

\section{METHODS}

A cross-sectional study was conducted involving 92 type 2 diabetic patients treated with insulin. The study used a questionnaire and blood samples. We measured the GA, HbA1C and random blood glucose levels. A multiple linear regression was used to analyze the data.

\section{RESULTS}

Mean HbA1c was $9.21 \pm 2.15 \%$, mean glycated albumin was $24.4 \pm 8.65 \%$, and mean blood glucose was $229.47 \pm 98.7 \mathrm{mg} / \mathrm{dL}$. Multiple linear regression tests showed that $\mathrm{HbA1c}(\mathrm{B}=5,544 ; \beta=0.121 ; \mathrm{p}=0.420)$ and $\mathrm{GA}(\mathrm{B}=5.899$; $\beta=0.517 ; p=0.001)$ was signigicantly corelated with random blood gucose, respectively, indicating that glycated albumin is significantly related to and has the greatest influence on glucose level.

\section{CONCLUSION}

Glycated albumin is correlated with and has greater influence on glucose level than does HbA1c. Glycated albumin could be a better marker for glycemic control than glycated hemoglobin in diabetic patients treated with insulin.
*Department of Clinical Pathology

Faculty of Medicine Trisakti

University

**Department of Pharmacology

and Pharmacy, Faculty of Medicine

Trisakti University

*** Department of Occupational

Medicine Faculty of Medicine

Trisakti University

\section{Corespodence:}

dr. Alvina, SpPK

Department of Clinical Pathology

of Medicine Trisakti University

Phone: 6221-5672731 ext 2604

Email:vina_march_dr@yahoo.com

Date of first submission, June 24, 2019 Date of final revised submission, March 23, 2020

Date of acceptance, March 23, 2020

This open access article is distributed under a Creative Commons AttributionNon Commercial-Share Alike 4.0

International License

Cite this article as: Alvina, Pusparini, Meiyanti, Merijanti LT. Glycated albumin is a better indicator for glucose levels than glycated hemoglobin in patients with diabetes mellitus on insulin therapy. Univ Med 2020;39:2733. doi: 10.18051/UnivMed.2020.v39. 27-33

Keywords: HbA1c, glycated albumin, blood glucose, diabetic type 2 patients 


\section{INTRODUCTION}

Diabetes mellitus (DM) is a metabolic disorder with a high worldwide incidence that constitutes a global health problem. By 2030 it is estimated that there will be around 439 million people suffering from DM. ${ }^{(1)}$ Diabetes mellitus is a metabolic disease caused by a lack or absence of the hormone insulin. ${ }^{(2)}$ The general picture of diabetes is chronic hyperglycemia that is associated with organ damage, such as renal failure, blindness, or amputation, which may increase its morbidity and mortality rates. . $^{(2,3)}$

Diabetes mellitus may be classified as type $1 \mathrm{DM}$, type $2 \mathrm{DM}$, gestational DM, and other specific types of diabetes (e.g. monogenic diabetes). Type $1 \mathrm{DM}$ is caused by autoimmune destruction of the pancreatic beta cells, type $2 \mathrm{DM}$ is caused by a defective insulin secretion, gestational DM is diabetes occurring in pregnancy, while the specific types of diabetes have varied etiologies. ${ }^{(4)}$

Type 2 diabetes mellitus has a high prevalence. This is associated with urbanization, in which the type $2 \mathrm{DM}$ population increases five to ten-fold because of changes in behavior, from traditional rural to urban. The risk factors that are epidemiologically altered are also increased, such as more and longer lasting obesity, lack of physical activity, and presence of hyperinsulinemia. ${ }^{(5)}$ To establish the diagnosis of diabetes, several examinations are required, among others random blood glucose level, fasting blood glucose level, the oral glucose tolerance test, and glycated hemoglobin (HbAlc) level. ${ }^{(6)}$

In type 2 DM pharmacotherapy may be administered to control the blood glucose level. The oral antihyperglycemic drugs that may be administered are the biguanids, glitazone, sulphonylureas, glinides, alpha glucosidase inhibitors, and combination therapy. In the case that oral antihyperglycemic therapy cannot control the blood glucose level, insulin may be administered. For therapeutic monitoring purposes, blood glucose, $\mathrm{HbA1c}$, and glycated albumin may be measured, glycated albumin being the most recent addition. ${ }^{(6,7)}$
Glycated hemoglobin (HbA1c) is an important marker for evaluating the fasting or postprandial plasma glucose over the preceding 120 days. ${ }^{(8)}$ Glycated hemoglobin is formed from the reaction between hemoglobin and glucose through a non-enzymatic reaction step between the N-terminal valine on the hemoglobin A beta chain and glucose. ${ }^{(9,10)}$

Glycated hemoglobin was discovered in the late 1960's as a glycemic control marker. Glycated hemoglobin is used for monitoring glycemic control in patients with diabetes and has been routinely used in the clinical laboratory since around 1977. ${ }^{(8)}$ Since 1988, glycated hemoglobin has been recommended by the American Diabetes Association for routine monitoring of patients with diabetes. ${ }^{(11)}$

There are a number of factors that may influence the HbA1c level, such as anemia, chronic renal failure, and variant hemoglobin. ${ }^{(11)}$ It is because of these factors possibly influencing its level that $\mathrm{HbAlc}$ does not reflect short-term glycemic changes and that its accuracy is reduced in diabetic patients with anemia or end-stage renal disease. ${ }^{(9)}$

Another method for evaluating glycemic control is the determination of glycated albumin (GA), which is not influenced by disturbances in hemoglobin metabolism. Glycated albumin reflects the blood glucose status of the preceding 2-4 weeks, whereas $\mathrm{HbA} 1 \mathrm{c}$ illustrates the blood glucose status of the preceding 3 months. Therefore GA reflects the glycemic status over a relatively shorter period of time than does $\mathrm{HbAlc}$, and does it more rapidly. The GAlevel is not affected by the serum protein level, since it is expressed as the glycated albumin to total serum albumin ratio. ${ }^{(9,12)}$

The GA level for therapeutic monitoring is beginning to be widely used. In the study carried out by Hamaguchi et al. ${ }^{(13)}$ that aimed to evaluate the glycated albumin level following sitagliptin therapy, the GA level was actually reduced within one month of treatment.

Intensive insulin therapy performed as initial treatment of 8 patients with type 2 diabetes mellitus 
and poor glycemic control, merely led to a small reduction in mean $\mathrm{HbA} 1 \mathrm{C}$ from $10.9 \%$ to $10.0 \%$, whereas mean glycated albumin was actually reduced from $35.6 \%$ to $25.0 \% .^{(14)}$ Yoon et al. ${ }^{(15)}$ reported that the deterioration in pancreatic beta cell function was correlated with the duration of DM and also with increased GA and the GA to $\mathrm{HbA1c}$ ratio, but not with $\mathrm{HbA1c}$ alone.

Based on the inconsistent results of previous studies, the aim of the present study was to determine the relationship of blood glucose and $\mathrm{HbA1c}$ with glycated albumin in patients with diabetes mellitus receiving insulin therapy.

\section{METHODS}

\section{Research design}

The design of this study was cross-sectional. The study was carried out at the Diabetes Polyclinic of Sumber Waras Hospital and the Prodia Clinical Laboratories from January until March 2019.

\section{Research subjects}

The inclusion criteria were male and female patients with DM, aged 30-80 years, duration of $\mathrm{DM}>1$ year, receiving insulin for $>1$ year. The exclusion criteria were patients with renal failure/ undergoing hemodialysis, liver cirrhosis, and hypothyroidism/hyperthyroidism. The sample size was determined based on the correlation coefficient of 0.75 between glycated albumin and fasting blood glucose level as found in a previous study. ${ }^{(16)}$ From $Z \alpha=1.96, Z \beta=0.84$ and drop-out $=20 \%$, the number of subjects required was 92 .

\section{Laboratory analysis}

The blood samples were drawn by venipuncture and the blood was collected in vacutainers with and without EDTA anticoagulant. The blood with EDTA was directly examined for HbA1c, whereas the blood without EDTA was centrifuged for 10 minutes at 2000 RPM to obtain the serum, which was examined for glycated albumin. The HbA1c level was assessed by high performance liquid chromatography (HPLC), ${ }^{(17)}$ which is based on the ion exchange principle. The sample is automatically mixed and diluted in the VARIANT II sampling station and injected into the analytical cartridge. The Chromatographic Station dual pumps deliver a programmed buffer gradient of increasing ionic strength to the cartridge, where the hemoglobins are separated based on their ionic interaction with the cartridge material. The separated hemoglobins pass through the flow cell of the filter photometer that measures changes in the absorbance at $415 \mathrm{~nm}$. An additional filter at $690 \mathrm{~nm}$ corrects the background absorbance. The VARIANT II Clinical Data Management program processes the data resulting from the respective analyses. Two-level calibration is used for adjusting the calculated HbA1c level. The sample results include the retention time of the detected peak and the chromatogram produced by the Clinical Data Management program for the respective samples. The A1c peaks are shaded (rendered in a darker color). The A1c peak area is calculated by means of an exponentially modified Gaussian algorithm that excludes the labile A1c and carbamylated A1c peak areas from the A1c peak area. ${ }^{(17)}$

The glycated albumin assessment method used was enzymatic colorimetry (Lucica GA-L; Asahi Kasei Pharma Co., Tokyo, Japan). The principle of the glycated albumin assay is the measurement of glycoalbumin, involving the conversion of glycated albumin (glycoalbumin) into glycated amino acid, then glycated amino acid $+\mathrm{O}_{2}+\mathrm{H}_{2} \mathrm{O}$ becomes glucosone + amino acid + $\mathrm{H}_{2} \mathrm{O}_{2}$, and finally $\mathrm{H}_{2} \mathrm{O}_{2}+4-\mathrm{AA}+\mathrm{TODB}\left(\mathrm{N}, \mathrm{N}^{\prime}-\right.$ bis(4-sulfobutyl)-3-methylanilin, disodium salt) yields a bluish-purple pigment $+\mathrm{H}_{2} \mathrm{O}$. The glycated amino acid resulting from glycoalbumin is determined by photometric measurement of the absorbance of the bluish-purple dye. ${ }^{(14)}$ The measured variables HbA1c and GA are expressed in $\%$. The measurement principle of blood glucose is automatic enzymatic photometry using the GOD-PAP method. The variable measured is the random blood glucose level. 


\section{Data analysis}

The test of normality was done with the Kolmogorov-Smirnov test, which showed that the data were normally distributed. Multiple linear regression analysis was used to determine the variable with the largest effect on glycated albumin. The level of significance used was 0.05 .

\section{Ethical clearance}

This study was approved by the Research Ethics Commission, Faculty of Medicine, Trisakti University, under no. 134/KER/FK/XII/2018.

\section{RESULTS}

In this study it was found that the majority of the respondents (59.8\%) were female, and had a mean age of $55.88 \pm 11.83$ years. Mean duration of DM was $11.04 \pm 7.62$ years and mean duration of insulin use was $3.88 \pm 4.00$ years. It was also found that mean $\mathrm{HbA} 1 \mathrm{c}$ level was $9.21 \pm 2.15$ $\%$, mean GA level $24.4 \pm 8.65 \%$ and mean random blood glucose $229.47 \pm 98.70 \mathrm{mg} / \mathrm{dL}$.

In Table 2 for the simple linear regression analysis it was found that $\mathrm{HbAlc}$, gender and GAwere correlated with random blood glucose $(\mathrm{p}<0.05)$. The variables that were significantly correlated with random blood glucose were subsequently entered into the multiple linear regression analysis model.

In Table 3 for the results of the multiple linear regression analysis, it was found that GA had a larger effect on random blood glucose $($ Beta $=$

Table 1. Distribution of subject characteristics $(n=112)$

\begin{tabular}{lc}
\hline Characteristic & $\mathbf{n}$ \\
\hline Age (years) & $55.88 \pm 11.83$ \\
Gender & \\
$\quad$ Male & $37(40.2)$ \\
$\quad$ Female & $55(59.8)$ \\
Duration of DM (years) & $11.04 \pm 7.62$ \\
Duration of insulin use (years) & $3.88 \pm 4.00$ \\
Random blood glucose Level & $229.47 \pm 98.7$ \\
(mg/dL) & \\
HbAlc (\%) & $9.21 \pm 2.15$ \\
Glycated albumin (\%) & $24.4 \pm 8.65$ \\
\hline Data presented as mean \pm SD
\end{tabular}

Data presented as mean $\pm \mathrm{SD}$, except for gender in $\mathrm{n}(\%)$
Table 2. Simple linear regression between respondent characteristic and blood glucose

\begin{tabular}{lcc}
\hline Variable & B & p value \\
\hline Age & -1.411 & 0.107 \\
Duration of DM & -0.385 & 0.283 \\
Duration of insulin therapy & -2.938 & 0.258 \\
HbAlc & 25.727 & 0.000 \\
Glycated albumin & 7.174 & 0.000 \\
Gender & 51.976 & 0.012 \\
\hline
\end{tabular}

$0.517 ; \mathrm{p}=0.000)$ than had HbA1c $($ Beta $=0.121$; $\mathrm{p}=0.420$ ).

\section{DISCUSSION}

In this study it was found that the majority of respondents $(59.8 \%)$ were female, with mean age of $55.88 \pm 11.83$ years. There were thus more patients with diabetes mellitus among the female respondents. This is in line with the study by Miharja et al. ${ }^{(18)}$ in that the prevalence of diabetes mellitus and abnormal glucose tolerance in Indonesia was found to be more prevalent in females as compared to males. These results differ from those of Chinese and Japanese studies where the prevalence of DM was higher in males than in females. This may be due to differences in dietary intake, physical activity, and other habitual activities. The Basic Health Research (Riset Kesehatan Dasar, Riskesdas) 2013 of the Ministry of Health (Kementrian Kesehatan) also found that according to gender, most of the patients with DM were women. ${ }^{(19)}$

The prevalence of diabetes mellitus and abnormal glucose tolerance in Indonesia increases with age. Eldery subjects are at higher risk of hyperglycemia, which is associated with a decrease in pancreatic functions, because the pancreas becomes less effective in producing insulin. ${ }^{(18)}$ The Riskesdas 2013 also found that the proportion of patients with DM increases with advancing age and was highest in the age group of 65-74 years. The proportion of the group with an abnormal glucose tolerance test was found to be increased with age, so that the highest proportion was in the age group of 65-74 years, then decreased somewhat. Similarly, the 
Table 3. Multiple linear regression between several respondent parameters and random blood glucose

\begin{tabular}{lccc}
\hline Variable & B & Beta & p value \\
\hline HbA1c & 5.544 & 0.121 & 0.420 \\
Glycated Albumin & 5.899 & 0.517 & 0.001 \\
Gender & 5.844 & 0.029 & 0.743 \\
\hline
\end{tabular}

Note : B: regression coefficient; Beta: standardized regression coefficient

proportion of abnormal fasting blood glucose also increased with age, with the highest proportion in the age group of 55-64 years, then decreasing somewhat in the next age groups. ${ }^{(19)}$

In the present study it was found that mean duration of DM was $11.04 \pm 7.62$ years, since $\mathrm{DM}$ is a chronic metabolic disease, due to the fact that the pancreas is incapable of producing insulin in adequate amounts or the body cannot effectively utilize the produced insulin. Diabetes is also one of the diseases that are known as the silent killers, because the patient with diabetes does not know or realize that he or she is suffering from diabetes and only knows when he or she suffers from complications. ${ }^{(19)}$

In simple regression analysis it was found that $\mathrm{HbAlc}$, gender, and glycated albumin were correlated with random blood glucose $(\mathrm{p}<0.05)$, but the results of multiple regression analysis showed that GA had the largest effect on random blood glucose, which may be due to the fact that serum albumin is strongly bound to glucose and the glycation reaction proceeds ten times as rapid as glycation of hemoglobin, so that GA is capable of more rapidly capturing fluctuations and changes in glycemic status than does HbAlc. ${ }^{(20)}$ Glycation depends on the degree and duration of hyperglycemia. The glucose level and the duration of exposure between protein and sugar is a factor in glycation for the lifespan of the protein. ${ }^{(2)}$ Mean albumin glycation rate is 9-10 times that of hemoglobin. ${ }^{(2,21)}$ The serum protein level does not influence the GA, because the GA is calculated from the ratio of glycated albumin level to total serum albumin. ${ }^{(20)}$

In the present study there was also found a significant correlation between GA and blood glucose. This may be have been caused by the shortened erythrocyte lifespan in diabetic patients with poor glycemic control, by delayed GLUT1-mediated glucose uptake by erythrocytes, resulting in lower degree of increase in $\mathrm{A} 1 \mathrm{c}$, by differences in glycation rates between hemoglobin and albumin in the blood, and possibly the involvement of a direct insulin effect on serum albumin metabolism. Intensive insulin therapy reduces glycemic excursions, stressing the need for minimizing fluctuations in glucose level. ${ }^{(22)}$

Human serum albumin is of benefit to patients with various disorders, where albumin limits oxidative damage. The albumin antioxidant properties are the result of limitation of reactive oxygen species (ROS) production by ligandbinding capacities as well as ROS scavenging through free radical trapping. In connection with ligand binding capacity, albumin binds readily to molecules such as metal ions, fatty acids, etc. Free $\mathrm{Cu}$ (II) and $\mathrm{Fe}$ (II) are very strong ROS generators when reacting with oxygen. ${ }^{(23)}$

Glycation and oxidation are the most common principal non-enzymatic mechanisms. Glycation, sometimes termed non-enzymatic glycosylation, is a simple process in which excess sugar molecules such as fructose or glucose are attached to normal protein or lipid molecules in the blood without enzymatic intervention. ${ }^{(23)}$

The study conducted by Ueda and Matsumoto on in-vitro glycation rates of human albumin and hemoglobin from three volunteers found that the production of GA was around 4.5 times higher than that of $\mathrm{HbAlc}$, after the administration of the same amount of glucose to the samples. This shows that under the same in-vitro glycation conditions, glycated albumin is produced more rapidly than $\mathrm{HbA1c} .^{(24)}$ 
According to Whaley-Connell and Sowers, within the individual glycemic measures, GA and $\mathrm{HbA1c}$ are strongly associated, but GA tends to trend with individual glucose profiles. ${ }^{(25)}$ Won et al. ${ }^{(26)}$ demonstrated a significant correlation between changes in GA over a 3-week period and in $\mathrm{HbAlc}$ over a 3-month period following intensive oral antidiabetic or insulin therapy. The study of Ake et al. ${ }^{(9)}$ also reports a strong positive correlation between GA and HbA1c. ${ }^{(9)}$

In the study conducted by Lee et al. ${ }^{(27)}$ it was found that the mean $\mathrm{GAn} / \mathrm{HbA} 1 \mathrm{c}$ ratio tends to increase with increasing $\mathrm{HbA} 1 \mathrm{c}$ level. The GA serum level increases 3-4\% for each $1 \%$ increase in $\mathrm{HbA} 1 \mathrm{c}$ level. Therefore, the increased GA/ $\mathrm{HbA} 1 \mathrm{c}$ ratio with high $\mathrm{HbA1c}$ may have been caused by an increase in GA level rather than HbA1c level, especially in patients with poor glycemic control. The study of Koga et al. ${ }^{(22)}$ showed that the $\mathrm{GA} / \mathrm{HbAlc}$ ratio was significantly higher in patients on insulin therapy than in patients on dietary treatment or oral hypoglycemic drugs.

According to the study of Koga et al. ${ }^{(12)} \mathrm{GA}$ decreases more rapidly than $\mathrm{HbA} 1 \mathrm{c}$ in cases of improved glycemic control and increases more rapidly in cases of poor short-term glycemic control. There are several situations and conditions that require GA as determinant of glycemic control status, such as fulminant type 1 DM onset, type $1 \mathrm{DM}$, type $2 \mathrm{DM}$ under insulin therapy, patients with postprandial hyperglycemia, hemolytic anemia, variant hemoglobin, chronic renal failure under hemodialysis, liver cirrhosis, iron deficiency anemia and patients treated with iron preparations, pregnant women and premenopausal women. ${ }^{(12)}$ The glycemic index may also be classified as long-term, intermediateterm and short-term glycemic indicator. The use of $\mathrm{HbAlc}$ as long-term glycemic indicator is due to the long erythrocyte lifespan of 120 days. For intermediate-term glycemic indices, glycated serum protein and albumin may be used to determine glycemic status over intermediate periods (2-4 weeks) that reflect the half-life of the respective molecules in serum. Glycated albumin with a half-life of 12-19 days may be a good glycemic index of recent ambient glycemia. ${ }^{(22)}$ Glycated albumin is at present a popular glycemic control index during intensive treatment. ${ }^{(27)}$

One limitation of the present study is that it did not investigate the factors that may affect $\mathrm{HbAlc}$ and GA, such as $\mathrm{Hb}$ level, red cell count, body mass index, blood pressure, lipid profile, protein intake, and albumin level. It is suggested that future studies should evaluate abovementioned factors in diabetic patients on oral antihyperglycemic therapy as well as in diabetic patients on insulin therapy.

\section{CONCLUSION}

There is a significant role and association between GA and random blood glucose among diabetic patients treated with insulin.

\section{CONFLICT OF INTEREST}

The authors declare no conflict of interest.

\section{ACKNOWLEDGMENTS}

Our heartfelt thanks to the Diabetes Polyclinic Team of Sumber Waras Hospital and the personnel of the Sumber Waras Hospital Laboratory.

\section{CONTRIBUTORS}

A wrote the proposal and coordinated the study locations. A, P, M, and LMT performed the data collection. A and $\mathrm{P}$ performed the statistical analysis, drafted the manuscript, and were responsible for data collection and implementation. All authors have read and approved the final manuscript.

\section{REFERENCES}

1. Chamnan P, Simmons RK, Forouhi NG, et al. Incidence of type 2 diabetes mellitus using 
proposed $\mathrm{HbA} 1 \mathrm{c}$ diagnostic criteria in the European Prospective Investigation of CancerNorfolk Cohort. Diabetes Care 2011;34:950-6. DOI: 10.2337/dc09-2326.

2. Freitas PAC, Ehlert LR, Camargo JL. Glycated albumin: a potential biomarker in diabetes. Arch Endocrinol Metab 2017;61:296-304. DOI: 10.1590/ 2359-3997000000272.

3. American Diabetes Association: Standard of medical care in diabetes-2016. Diabetes Care 2016; 39 Suppl 1:S1-S112. DOI: 10.2337/dc14-S081.

4. Baynest HW. Classification, pathophysiology, diagnosis and management of diabetes mellitus. J Diabetes Metab 2015;6:1-9. DOI: 10.4172/21556156.1000541.

5. International Diabetes Federation. Diabetes risk factors. Brussels: International Diabetes Federation; 2019.

6. American Diabetes Association. Classification and diagnosis of diabetes. Diabetes Care 2015;38 Suppl 1:S8-16|DOI: 10.2337/dc15-S005.

7. Gul A, Sharif N, Zahoorullah, et al. Diabetes: comparison of $\mathrm{HbA} 1 \mathrm{c}$ and serum glycated albumin levels as monitoring tool. Prof Med J 2018;25:109-14. DOI: 10.29309/TPMJ/18.4263.

8. Indranila KS. Glycated hemoglobin A1c as a biomarker predictor for diabetes mellitus, cardiovascular disease and inflammation. Indones J Clin Pathol Med Lab 2017;23:191-6. DOI: http:/ /dx.doi.org/10.24293/ijcpml.v23i2.1145.

9. Ake A, Saraswati MR, Widiana IGR. Glycated albumin sebagai penanda kontrol glikemik pada penderita diabetes melitus tipe 2. Udayana J Int Med 2017;1:1-7. DOI: https://doi.org/10.36216/ jpd.v1i1.10.

10. Mahajan RD, Mishra B. Using glycated hemoglobin HbAlc for diagnosis of diabetes mellitus: an Indian perspective. Int J Biol Med Res 2011;2:508-12.

11. Welsh KJ, Kirkman MS, Sacks DB. Role of glycated proteins in the diagnosis and management of diabetes: research gaps and future directions. Diabetes Care 2016;39:1299-306. DOI: 10.2337/dc15-2727.

12. Koga M, Kasayama M. Clinical impact of glycated albumin as another glycemic control marker. Endocrine J 2010;57:751-62.

13. Hamaguchi T, Koga M, Murai J, et al. Estimation of $\mathrm{HbA} 1 \mathrm{c}$ response to sitagliptin by change in glycated albumin level for 2 weeks. J Diabetes Investig 2012;3:175-8. DOI: 10.1111/j.2040$11242011.00167 x .2012$.

14. Kohzuma T, Koga M. Lucica GA-L glycated albumin assay kit: a new diagnostic test for diabetes mellitus. Mol Diagn Ther 2010;14:49-51. DOI: 10.2165/11317390-000000000-00000.
15. Yoon HJ, Lee YH, Kim KJ, et al. Glycated albumin levels in patients with type 2 diabetes increase relative to HbA1c with time. Biomed Res Int 2015; 2015:576306. DOI: 10.1155/2015/576306.

16. Paroni R, Ceriotti F, Galanello R, et al. Performance characteristics and clinical utility of an enzymatic method for the measurement of glycated albumin in plasma. Clin Biochem 2007;40:1398-405. DOI: 10.1016/j.clinbiochem.2007.08.001.

17. Bio Rad. D-10 Hemoglobin testing system for hemoglobin A1c. Bio-Rad Laboratories, Inc.;2019.

18. Mihardja L, Soetrisno U, Soegondo S. Prevalence and clinical profile of diabetes mellitus in productive aged urban Indonesians. J Diabetes Invest 2014;5:507-12. DOI: 10.1111/jdi.12177.

19. Kementerian Kesehatan RI InfoDatin Pusat Data and Informasi. Situasi and analisis diabetes. Jakarta : Kementerian Kesehatan RI InfoDatin Pusat Data and Informasi;2014.

20. Simanjuntak S, Darmanta B, Kartikasari EY, et al. Hubungan glycated albumin dengan $\mathrm{HbA1c}$ pada pasien diabetes mellitus tipe II. Jurnal Kedokteran Methodist 2017;9:631-8.

21. Rondeau P, Bourdon E. The glycation of albumin: structural and functional impacts. Biochimie 2011; 93:645-58. DOI: 10.1016/j.biochi.2010.12.003.

22. Koga M, Murai J, Saito H, et al. Glycated albumin and glycated hemoglobin are influenced differently by endogenous insulin secretion in patients with type 2 diabetes. Diabetes Care 2010;33:270-2. DOI: 10.2337/dc09-1002.

23. Kim KJ, Lee BW. The roles of glycated albumin as intermediate glycation index and pathogenic protein. Diabetes Metab J 2012;36:98-107. DOI: 10.4093/dmj.2012.36.2.98.

24. Ueda Y, Matsumoto H. Recent topics in chemical and clinical research on glycated albumin. J Diabetes Sci Technol 2015;9:177-82. DOI: 10.1177/ 1932296814567225.

25. Whaley-Connell A, Sowers JR. Implications for glucose measures in the Diabetes Control and Complications Trial/Epidemiology of Diabetes Interventions and Complication Study. Diabetes 2014;63:45-7. DOI: 10.2337/db13-1497.

26. Won HK, Kim KJ, Lee BW, et al. Reduction in glycated albumin can predict change in HbAlc: comparison of oral hypoglycaemic agent and insulin treatments. Diabet Med 2012;29:74-9. DOI: 10.1111/j.1464-5491.2011.03386.x.

27. Lee EY, Lee BW, Kim D, et al. Glycated albumin is a useful glycation index for monitoring fluctuating and poorly controlled type 2 diabetic patients. Acta Diabetol 2011;48:167-72. DOI: 10.1007/ s00592-010-0242-0. 